\title{
Nutritional and phytochemical profiles and biological activities of Moringa oleifera Lam. edible parts from Guinea-Bissau (West Africa)
}

\author{
Ângela Fernandes ${ }^{\mathrm{a}, *}$, Aducabe Bancessi ${ }^{\mathrm{b}, \mathrm{c}}$, José Pinela ${ }^{\mathrm{a}}$, Maria Inês Dias ${ }^{\mathrm{a}}$, Ângela Liberal ${ }^{\mathrm{a}}$, \\ Ricardo C. Calhelha ${ }^{a}$, Ana Ćirićc ${ }^{\text {, Marina Sokovićc }}{ }^{\text {, Luís Catarino }}{ }^{c}$, Isabel C.F.R. Ferreira ${ }^{a}$, \\ Lillian Barros ${ }^{\mathrm{a}, *}$ \\ ${ }^{a}$ Centro de Investigação de Montanha (CIMO), Instituto Politécnico de Bragança, Campus de Santa Apolónia, 5300-253 Bragança, Portugal \\ ${ }^{\mathrm{b}}$ Nova School of Business and Economics, NOVA University of Lisbon, Campus de Carcavelos, Rua da Holanda, n. 1, 2775-405 Carcavelos, Portugal \\ ${ }^{\mathrm{c}}$ Centre for Ecology, Evolution and Environmental Changes (cE3c), Faculty of Sciences, University of Lisbon, Campo Grande, $1749-016$ Lisbon, Portugal \\ ${ }^{\mathrm{d}}$ Institute for Biological Research "Siniša Stanković" - National Institute of Republic of Serbia, University of Belgrade, Bulevar Despota Stefana 142, 11000 Belgrade, \\ Serbia
}

\section{A R T I C L E I N F O}

\section{Keywords:}

Moringa oleifera

Famine food

Nutritional composition

Phenolic profile

Antioxidant/anti-inflammatory activity

Cytotoxicity

\begin{abstract}
A B S T R A C T
Moringa oleifera is an edible medicinal plant used to fight malnutrition in Africa. In this study, M. oleifera flowers, fruits and seeds from Guinea-Bissau were characterized for their nutritional composition and hydroethanolic and aqueous extracts were prepared to investigate the phenolic profiles and bioactivities. Seeds presented higher levels of proteins $(\sim 31 \mathrm{~g} / 100 \mathrm{~g} \mathrm{dw})$, fat $(\sim 26 \mathrm{~g} / 100 \mathrm{~g} \mathrm{dw})$ and flavan-3-ol derivatives, while carbohydrates, proteins, citric acid, and glycosylated flavonoids were abundant in fruits and flowers, these last samples also being rich in $\alpha$-tocopherol ( $\sim 18 \mathrm{mg} / 100 \mathrm{~g} \mathrm{dw})$. Some of the identified polyphenols had never been described in M. oleifera. In general, hydroethanolic extracts contained more polyphenols and were more active against lipid peroxidation, NO production, and tumour cells growth. Significant antimicrobial effects against the tested bacteria and fungi strains were displayed by both hydroethanolic and aqueous extracts. The M. oleifera potential to fight malnutrition and health issues was highlighted.
\end{abstract}

\section{Introduction}

The search for plants and plant-based products that can face the raising necessities of food and medicines in a context of climate changes and food scarcity is nowadays a major challenge in Africa where persist malnutrition problems (Muyonga, Nansereko, Steenkamp, Manley, \& Okoth, 2016). In this context, Moringa oleifera Lam. (Moringaceae) appears as a species with nutritional, medicinal and agronomic value. This fast-growing, deciduous tree is native to the Indian subcontinent and Pakistan, and has become naturalized in the tropical and subtropical areas around the world, namely in many African countries due to its easy adaptability and tolerance to a wide range of environmental conditions regarding climate and soil (Daba, 2016).

M. oleifera is one of the most auspicious plants used as a suitable alternative for preventing and alleviating malnutrition challenges, especially hidden hunger health issues (Padayachee \& Baijnath, 2020). It is considered to be a "Miracle tree" or "Tree of life" due to the substantial beneficial effects that it has on health, but also due to its potential use in water sanitation and environmental conservation (Daba,
2016). M. oleifera preparations have been reported in the scientific literature as having a wide range of pharmacological properties, including antimicrobial, hypotensive, hypoglycemic, immunomodulatory, and anti-inflammatory activities. In addition, all $M$. oleifera parts (including leaves, fruits, seeds, pods, and flowers) have been used in traditional foods and dishes for human consumption (Daba, 2016).

The leaves and seeds are eaten fresh, powdered or cooked and contain a varied profile of nutrients and health-promoting compounds, such as fatty acids, tocopherols, $\beta$-carotene, and phenolic compounds. The fruits are fibrous and traditionally used to treat digestive problems and prevent colon cancer. Flower extracts, in turn, are used in culinary preparations to enhance the taste and colour of dishes (Padayachee \& Baijnath, 2020; Ziani et al., 2019). These M. oleifera organs are also known to be good sources of secondary metabolites, including terpenoids, flavonoids, tannins, anthocyanins, and proanthocyanidins (Ajibade, Arowolo, \& Olayemi, 2013). These bioactive compounds contribute to the therapeutic and medicinal properties of $M$. oleifera and may justify its uses by the indigenous system of medicine in the

\footnotetext{
* Corresponding authors.

E-mail addresses: afeitor@ipb.pt (Â. Fernandes), lillian@ipb.pt (L. Barros).
} 
treatment of common ailments and disorders, such as anaemia, asthma, diarrhea, skin infections, headaches, swelling, hysteria, cholera, scurvy, respiratory disorders, diabetes, cough, sore throat, and chest congestion (Padayachee \& Baijnath, 2020). Therefore, this edible medicinal plant appears as a natural remedy easily accessible to populations in developing countries that need basic healthcare, especially in areas where Western medicine is inaccessible or expensive (Padayachee \& Baijnath, 2020). Curiously, $M$. oleifera seed powder is used as a purifying agent in the treatment of water, being able to eliminate pathogenic bacteria up to $99 \%$, whereas fresh leaves can be used to extract a juice used as a growth hormone (or soil fertilizer) able to increase crop yields by 25-35\% (Daba, 2016).

In Guinea-Bissau (West Africa), the awareness of local populations about the medicinal and nutritional properties of $M$. oleifera has increased in the last years, where the trade of seeds and dried and crushed leaves is under development. Despite this, the exploitation of the different edible and medicinal parts of this plant in this country is far to reach their full potential (Bancessi, Bancessi, Baldé, \& Catarino, 2020). Therefore, due to the multiple traditional uses and applications of $M$. oleifera, this study was performed to determine the detailed nutritional and chemical composition (proximate constituents, free sugars, organic acids, tocopherols, fatty acids, and phenolic compounds) of seed, flower and fruit samples collected in two distinct locations in Guinea-Bissau using official methods of food analysis and advanced chromatographic techniques. In addition, the antioxidant, anti-inflammatory, cytotoxic, and antimicrobial activities of hydroethanolic, infused and decocted extracts prepared with the three $M$. oleifera organs were assessed in vitro using different cellular assays and food-borne microorganisms. In this way, it is intended to demonstrate and validate the food and medicinal potential of $M$. oleifera, which can have a direct impact on the food security of local African populations and be useful for the development of new functional foods and nutraceuticals.

\section{Material and methods}

\subsection{Sampling and samples preparation}

M. oleifera seeds, flowers and immature fruits (Fig. 1) were collected

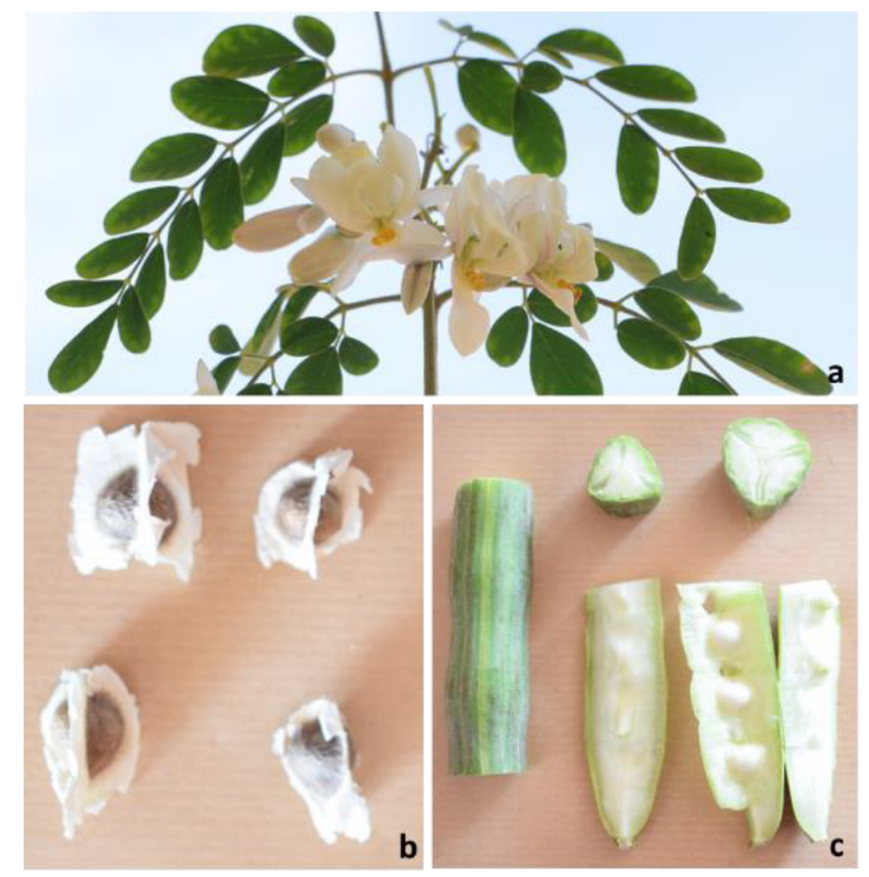

Fig. 1. Edible parts of Moringa oleifera characterized in this study: a) flowers; $b$ ) seeds; and c) Immature fruits. in early May 2019 in two locations in Guinea-Bissau: Granja (11 ${ }^{\circ}$ $52^{\prime} 02^{\prime \prime} \mathrm{N}$; $15^{\circ} 36^{\prime} 06^{\prime \prime} \mathrm{W}$ ), a state farm inside Bissau urban area, and in a homegarden in Ponta Romana, Quinhamel, located in the countryside $\left(11^{\circ} 54^{\prime} 18^{\prime \prime} \mathrm{N} ; 15^{\circ} 49^{\prime} 45^{\prime \prime} \mathrm{W}\right)$. The two collecting sites are about $30 \mathrm{~km}$ apart and the soil and climatic conditions in both sites are similar (ferralsols, rainfall c. $1500 \mathrm{~mm}$ per year). The main differences are the urban vs. rural environment and the fact that in Granja the harvested trees were isolated, with direct sunlight during most of the day and in Ponta Romana the samples were taken from trees of a living fence in a homegarden, with less direct sunlight. The plant samples were then lyophilized (FreeZone 4.5, Labconco, MO, USA) and reduced to a fine powder that was stored in well-sealed plastic bags at $-20{ }^{\circ} \mathrm{C}$ in the dark until further analysis.

\subsection{Nutritional value and energy assessment}

The $M$. oleifera edible samples were analysed for moisture, protein, fat, and ash contents following the AOAC analytical procedures (AOAC International, 2016). Total carbohydrates were calculated by difference and the energetic value was calculated according to the Regulation (EC) No. 1169/2011 of The European Parliament and of the Council as follows: energy (kcal/100 $\mathrm{g}$ dried weight $(\mathrm{dw}))=4 \times(\mathrm{g}$ protein $+\mathrm{g}$ carbohydrate $)+9 \times(\mathrm{g}$ fat $)$.

\subsection{Chromatographic analysis of free sugars, organic acids, fatty acids, and tocopherols}

Free sugars were analysed in a high-performance liquid chromatography (HPLC) system (Knauer, Smartline system 1000, Berlin, Germany) coupled to a refractive index detector (Smartline System 1000), using the internal standard (melezitose, Sigma-Aldrich, St Louis, MO, USA) method previously described by Spréa et al. (2020). Data were recorded and processed using Clarity 2.4 software (DataApex, Prague, Czech Republic) and the results were expressed as $\mathrm{g}$ per $100 \mathrm{~g}$ dw.

Organic acids were analysed by ultra-fast liquid chromatography (Shimadzu 20A series, Shimadzu Corporation, Kyoto, Japan) coupled to a diode-array detector operating in the conditions described by Spréa et al. (2020). The compounds were identified by comparing their retention time and UV-Vis spectra with those of standards (oxalic, malic, ascorbic, citric, and fumaric acids, Sigma-Aldrich, St. Louis MO, USA) and quantified based on calibration curves obtained by plotting the peak area recorded at $245 \mathrm{~nm}$ for ascorbic acid and at $215 \mathrm{~nm}$ for the remaining acids against concentration. Data were recorded and processed using LabSolutions Multi LC-Photodiode Array (PDA) software (Shimadzu Corporation, Kyoto, Japan) and the results were given as $\mathrm{g}$ per $100 \mathrm{~g} \mathrm{dw}$.

The fatty acids profile was determined by gas-liquid chromatography (DANI 1000, Switzerland) coupled to a flame ionization detector (FID) operating in the conditions previously described by Spréa et al. (2020). Data were recorded and processed using Clarity 4.0 software and the results were given as relative percentage of each fatty acid.

Tocopherols were determined using the internal standard (tocol, Matreya, Pleasant Gap, PA, USA) method and the HPLC system (Smartline System 1000, Knauer, Berlin, Germany) coupled to a fluorescence detector (FP-2020, Jasco, Easton, USA) programmed for excitation at $290 \mathrm{~nm}$ and emission at $330 \mathrm{~nm}$, as previously described by Spréa et al. (2020). Data were recorded and processed using Clarity 2.4 software and the results were given as mg per $100 \mathrm{~g} \mathrm{dw}$.

\subsection{Preparation of $M$. oleifera hydroethanolic and aqueous extracts}

The $M$. oleifera seed, flower and immature fruit samples were prepared in hydroethanolic, infused and decocted extracts to evaluate their composition in phenolic compounds and the in vitro bioactive 
properties. These preparation/extraction methods were selected according to the traditional uses of the different parts of the plant (Dhakar et al., 2011; Ilyas, Arshad, Saeed, \& Iqbal, 2015; Lim, 2014).

To prepare the hydroethanolic extracts, each sample $(2 \mathrm{~g})$ was mixed with ethanol/water solution $(80: 20, v / v ; 30 \mathrm{~mL})$ and stirred for $1 \mathrm{~h}$ at room temperature. After filtering the supernatant through Whatman filter paper No 4, the residue was re-extracted and the combined filtrates were concentrated under reduced pressure (rotary evaporator Büchi R-210, Switzerland) at $40{ }^{\circ} \mathrm{C}$ and the aqueous phase was subsequently lyophilized (Iyda, Fernandes, Ferreira et al., 2019).

For decoctions, each sample (2 g) was boiled with distilled water $(100 \mathrm{~mL})$ for $5 \mathrm{~min}$ in heating plate (VELP Scientific) and then filtrated through Whatman filter paper No 4. The obtained decoctions were frozen and lyophilized (Iyda, Fernandes, Ferreira et al., 2019).

Only seeds and flowers were used to prepare infusions. The samples $(2 \mathrm{~g})$ were infused with freshly boiled distilled water $(100 \mathrm{~mL})$, left aside for $5 \mathrm{~min}$ and subsequently filtered through Whatman filter paper No 4. The resulting extracts were frozen and lyophilized (Adouni et al., 2018).

\subsection{HPLC-DAD-ESI/MS ${ }^{n}$ analysis of phenolic compounds}

Phenolic compounds were analysed in hydroethanolic, infused and decocted extracts, which were redissolved in ethanol/water (80:20, $v$ / $v$ ) and water, respectively, to a final concentration of $10 \mathrm{mg} / \mathrm{mL}$ and filtered using $0.22 \mu \mathrm{m}$ disposable filter disks. The analysis was performed in a HPLC system (Dionex Ultimate 3000 UPLC, Thermo Scientific, San Jose, California, USA) coupled with a diode-array detector (DAD, using 280 and $370 \mathrm{~nm}$ as preferred wavelengths) and a Linear Ion Trap (LTQ XL) mass spectrometer (MS, Thermo Finnigan, San Jose, CA, USA) equipped with an electrospray ionization (ESI) source. Separation was made in a Waters Spherisorb S3 ODS-2 C18 column ( $3 \mu \mathrm{m}, 4.6 \mathrm{~mm} \times 150 \mathrm{~mm}$; Waters, Milford, MA, USA). The operating conditions were previously described by Bessada, Barreira, Barros, Ferreira, and Oliveira (2016), as well as the identification and quantification procedures. The results were given as $\mathrm{mg}$ per $\mathrm{g}$ of extract.

\subsection{Evaluation of bioactive properties in vitro}

\subsubsection{Antioxidant activity}

Two cell-based assays were performed to measure the in vitro antioxidant activity of the extracts $(0.1563-5 \mathrm{mg} / \mathrm{mL})$, following methodologies formerly described by Spréa et al. (2020) and Lockowandt et al. (2019). The extracts capacity to inhibit the formation of thiobarbituric acid reactive substances (TBARS) was assessed using porcine brain cell tissues as oxidizable substrates, and the results were expressed as half maximal effective extract concentration $\left(\mathrm{EC}_{50}\right)$ values $(\mathrm{mg} / \mathrm{mL})$. The oxidative haemolysis inhibition assay (OxHLIA) was performed to assess the extracts capacity to protect sheep erythrocytes from the AAPH (2,2'-azobis(2-methylpropionamidine) dihydrochloride)-induced oxidative haemolysis. Half maximal inhibitory concentration $\left(\mathrm{IC}_{50}\right)$ values $(\mu \mathrm{g} / \mathrm{mL})$ were calculated for time intervals $(\Delta t)$ of 60 and $120 \mathrm{~min}$ and translate the extract concentration required to keep $50 \%$ of the erythrocyte population intact for 60 and $120 \mathrm{~min}$. Trolox (Sigma-Aldrich, St. Louis, MO, USA) was used as a positive control.

\subsubsection{Nitric oxide (NO)-production inhibition activity}

The anti-inflammatory activity of the extracts (at concentrations up to $400 \mu \mathrm{g} / \mathrm{mL}$ ) was assessed based on the nitric oxide (NO) production by a lipopolysaccharide (LPS)-stimulated murine macrophage (RAW 264.7) cell line. The NO production was quantified based on the nitrite concentration using the Griess Reagent System kit containing sulphanilamide, $N$-1-naphthylethylenediamine dihydrochloride and nitrite solutions, following a procedure previously described by Corrêa et al. (2015). Dexamethasone (Sigma-Aldrich, St. Louis, MO, USA) was used as a positive control, while no LPS was added in negative controls. The effect of the tested extracts in NO basal levels was also assessed by performing the assay in the absence of LPS. The results were expressed as $\mathrm{IC}_{50}$ values $(\mu \mathrm{g} / \mathrm{mL})$, which correspond to the extract concentration providing $50 \%$ of $\mathrm{NO}$ production inhibition.

\subsubsection{Cytotoxic activity}

The extracts cytotoxicity was assessed by the sulforhodamine B (Sigma-Aldrich, St. Louis, MO, USA) assay against four human tumour cell lines (acquired from Leibniz-Institut DSMZ), namely MCF-7 (breast adenocarcinoma), NCI-H460 (non-small cell lung cancer), HeLa (cervical carcinoma), and HepG2 (hepatocellular carcinoma), following a protocol previously described by Spréa et al. (2020). Ellipticine (SigmaAldrich, St. Louis, MO, USA) was used as a positive control. The same assay was also used to evaluate the hepatotoxicity of the extracts against a non-tumour cell line (PLP2, porcine liver primary cells) obtained as described by Spréa et al. (2020). The extract concentration $(\mu \mathrm{g} / \mathrm{mL})$ causing $50 \%$ cell growth inhibition $\left(\mathrm{GI}_{50}\right)$ was calculated and used to express the results.

\subsubsection{Antimicrobial activity}

The extracts were redissolved in 5\% dimethyl sulfoxide (DMSO) to a concentration of $10 \mathrm{mg} / \mathrm{mL}$ and further diluted. The microdilution method (Soković, Glamočlija, Marin, Brkić, \& van Griensven, 2010) was performed to assess the antimicrobial activity against the Gram-negative bacteria Escherichia coli (ATCC 35210), Salmonella Typhimurium (ATCC 13311) and Enterobacter cloacae (ATCC 35030), and the Grampositive Staphylococcus aureus (ATCC 6538), Bacillus cereus (clinical isolate) and Listeria monocytogenes (NCTC 7973). The antifungal activity was assessed against Aspergillus fumigatus (ATCC 1022), Aspergillus ochraceus (ATCC 12066), Aspergillus niger (ATCC 6275), Penicillium funiculosum (ATCC 36839), Penicillium ochrochloron (ATCC 9112), and Penicillium aurantiogriseum (food isolate) (Corrêa et al., 2015). The minimum extract concentrations that completely inhibited bacterial growth (MICs) were determined by a colorimetric microbial viability assay, and minimum bactericidal concentration (MBC) and minimum fungicidal concentration (MFC) were also calculated. Streptomycin, ampicillin, ketoconazole and bifonazole (Sigma-Aldrich, St. Louis, MO, USA) were used as positive controls, and 5\% DMSO was used as a negative control.

\subsection{Statistical analysis}

Three samples were used for each analysis and all the assays were carried out in triplicate. The results were presented as mean values and standard deviation. A Student's $t$-test was applied to assess significant difference among plant samples with a different geographic origin (Quinhamel and Bissau), with $\alpha=0.05$. In the bioactive assays, a oneway analysis of variance (ANOVA) was applied, followed by Tukey's HSD test, with $\alpha=0.05$, to assess significant differences between hydroethanolic, infused and decocted extracts. The analysis was carried out using SPSS v. 22.0 program SPSS Statistics software (IBM Corp., Armonk, NY, USA).

\section{Results and discussion}

\subsection{Nutritional composition of M. oleifera edible parts}

Since the plants composition is affected by different factors, such as the edaphoclimatic conditions of the different growing sites, agricultural practices, harvesting period, and genetic characteristics, among others (Iyda, Fernandes, Calhelha et al., 2019), the studied samples of M. oleifera were collected at two distinct locations in Guinea-Bissau. Table 1 presents the proximal composition of the M. oleifera seeds, flowers, and fruits collected in Quinhamel and Bissau. Carbohydrates were found to be major constituents in all studied samples; the highest 
Table 1

Nutritional value and composition in free sugars, organic acids, main fatty acids, and tocopherols of $M$. oleifera edible parts.

\begin{tabular}{|c|c|c|c|c|c|c|c|c|c|}
\hline & \multicolumn{2}{|l|}{ Seeds } & \multirow{2}{*}{$\begin{array}{l}\text { Student's } t \text { - } \\
\text { test }\end{array}$} & \multicolumn{2}{|l|}{ Flowers } & \multirow{2}{*}{$\begin{array}{l}\begin{array}{l}\text { Student's } t \text { - } \\
\text { test }\end{array} \\
p \text {-value }\end{array}$} & \multicolumn{2}{|l|}{ Fruits } & \multirow{2}{*}{$\begin{array}{l}\begin{array}{l}\text { Student's } t \text { - } \\
\text { test }\end{array} \\
p \text {-value }\end{array}$} \\
\hline & Quinhamel & Bissau & & Quinhamel & Bissau & & Quinhamel & Bissau & \\
\hline Moisture (\%) & np & np & - & $81.4 \pm 0.5$ & $81.4 \pm 0.1$ & 0.851 & $79.0 \pm 0.4$ & $76.8 \pm 0.9$ & 0.006 \\
\hline Fat $(g / 100 \mathrm{~g})$ & $26.0 \pm 0.1$ & $26.6 \pm 0.1$ & 0.001 & $5.27 \pm 0.07$ & $5.02 \pm 0.05$ & 0.002 & $4.3 \pm 0.1$ & $2.67 \pm 0.06$ & $<0.001$ \\
\hline Proteins (g/100 g) & $30.0 \pm 0.6$ & $31.88 \pm 0.08$ & 0.002 & $21.3 \pm 0.4$ & $19.83 \pm 0.01$ & 0.001 & $19.79 \pm 0.04$ & $19.49 \pm 0.06$ & 0.476 \\
\hline Ash $(g / 100 \mathrm{~g})$ & $2.8 \pm 0.1$ & $2.67 \pm 0.01$ & 0.001 & $7.93 \pm 0.09$ & $7.95 \pm 0.07$ & 0.346 & $6.31 \pm 0.06$ & $5.93 \pm 0.05$ & $<0.001$ \\
\hline Carbohydrates (g/100 g) & $41.2 \pm 0.3$ & $38.85 \pm 0.03$ & $<0.001$ & $65.5 \pm 0.3$ & $67.2 \pm 0.1$ & 0.001 & $79.6 \pm 0.1$ & $71.91 \pm 0.04$ & $<0.001$ \\
\hline Energy (kcal/100 g) & $518.3 \pm 0.4$ & $522.2 \pm 0.5$ & $<0.001$ & $394.6 \pm 0.5$ & $393.2 \pm 0.1$ & 0.007 & $396.3 \pm 0.5$ & $389.7 \pm 0.3$ & $<0.001$ \\
\hline Fructose $(\mathrm{g} / 100 \mathrm{~g})$ & nd & nd & - & $2.19 \pm 0.02$ & $1.51 \pm 0.01$ & $<0.001$ & $3.00 \pm 0.04$ & $2.86 \pm 0.04$ & 0.003 \\
\hline Glucose (g/100 g) & $0.15 \pm 0.05$ & $0.16 \pm 0.04$ & 0.651 & $6.01 \pm 0.07$ & $3.30 \pm 0.04$ & $<0.001$ & $8.02 \pm 0.04$ & $10.03 \pm 0.08$ & $<0.001$ \\
\hline Sucrose $(\mathrm{g} / 100 \mathrm{~g})$ & $1.17 \pm 0.04$ & $1.70 \pm 0.03$ & $<0.001$ & $2.93 \pm 0.09$ & $5.52 \pm 0.07$ & $<0.001$ & $5.03 \pm 0.04$ & $4.92 \pm 0.01$ & 0.005 \\
\hline Trehalose $(\mathrm{g} / 100 \mathrm{~g})$ & nd & nd & - & $0.82 \pm 0.03$ & $0.75 \pm 0.01$ & 0.005 & $0.63 \pm 0.01$ & $1.01 \pm 0.05$ & $<0.001$ \\
\hline Total sugars $(\mathrm{g} / 100 \mathrm{~g})$ & $1.32 \pm 0.09$ & $1.86 \pm 0.06$ & $<0.001$ & $12.0 \pm 0.2$ & $11.1 \pm 0.1$ & 0.001 & $16.7 \pm 0.1$ & $18.8 \pm 0.2$ & $<0.001$ \\
\hline Oxalic acid (g/100 g) & $10.44 \pm 0.05$ & $10.6 \pm 0.2$ & 0.153 & $0.77 \pm 0.01$ & $1.82 \pm 0.01$ & $<0.001$ & $0.66 \pm 0.01$ & $1.18 \pm 0.01$ & $<0.001$ \\
\hline Malic acid (g/100 g) & nd & nd & - & $1.79 \pm 0.02$ & $1.29 \pm 0.02$ & $<0.001$ & $1.84 \pm 0.03$ & $1.30 \pm 0.01$ & $<0.001$ \\
\hline Ascorbic acid (g/100 g) & nd & nd & - & $0.25 \pm 0.01$ & $0.19 \pm 0.01$ & $<0.001$ & $0.35 \pm 0.01$ & $0.65 \pm 0.02$ & $<0.001$ \\
\hline Citric acid (g/100 g) & nd & nd & - & $3.05 \pm 0.01$ & $3.12 \pm 0.02$ & 0.001 & $1.84 \pm 0.02$ & $2.62 \pm 0.01$ & $<0.001$ \\
\hline Fumaric acid $(\mathrm{g} / 100 \mathrm{~g})$ & $\operatorname{tr}$ & $\operatorname{tr}$ & - & $\operatorname{tr}$ & $\operatorname{tr}$ & - & $\operatorname{tr}$ & $\operatorname{tr}$ & - \\
\hline $\begin{array}{l}\text { Total organic acids }(\mathrm{g} / \\
100 \mathrm{~g})\end{array}$ & $10.44 \pm 0.05$ & $10.6 \pm 0.2$ & 0.153 & $5.85 \pm 0.01$ & $6.42 \pm 0.01$ & $<0.001$ & $4.71 \pm 0.02$ & $5.75 \pm 0.02$ & $<0.001$ \\
\hline $\mathrm{C} 16: 0$ & $6.1 \pm 0.2$ & $7.0 \pm 0.2$ & 0.002 & $19.7 \pm 0.1$ & $21.6 \pm 0.2$ & $<0.001$ & $12.8 \pm 0.2$ & $10.4 \pm 0.2$ & $<0.001$ \\
\hline C18:0 & $5.53 \pm 0.06$ & $6.5 \pm 0.2$ & $<0.001$ & $4.64 \pm 0.01$ & $4.23 \pm 0.09$ & $<0.001$ & $4.67 \pm 0.06$ & $4.73 \pm 0.07$ & 0.221 \\
\hline C18:1n9 & $71.6 \pm 0.2$ & $69.4 \pm 0.4$ & $<0.001$ & $25.8 \pm 0.1$ & $20.32 \pm 0.01$ & $<0.001$ & $52.4 \pm 0.6$ & $48.8 \pm 0.1$ & $<0.001$ \\
\hline C18:2n6 & $0.65 \pm 0.03$ & $0.69 \pm 0.06$ & 0.192 & $15.1 \pm 0.1$ & $14.4 \pm 0.5$ & 0.023 & $7.42 \pm 0.08$ & $8.5 \pm 0.3$ & $<0.001$ \\
\hline C18:3n3 & $0.21 \pm 0.02$ & $0.195 \pm 0.005$ & 0.116 & $16.4 \pm 0.1$ & $22.3 \pm 0.3$ & $<0.001$ & $6.67 \pm 0.09$ & $6.3 \pm 0.4$ & $<0.001$ \\
\hline $\mathrm{C} 22: 0$ & $7.0 \pm 0.2$ & $6.98 \pm 0.09$ & 0.446 & $5.6 \pm 0.2$ & $5.4 \pm 0.5$ & 0.414 & $7.43 \pm 0.09$ & $9.1 \pm 0.1$ & $<0.001$ \\
\hline $\mathrm{C} 24: 0$ & $1.43 \pm 0.08$ & $1.33 \pm 0.01$ & 0.039 & $6.0 \pm 0.3$ & $5.0 \pm 0.3$ & 0.005 & $1.67 \pm 0.09$ & $3.6 \pm 0.2$ & $<0.001$ \\
\hline SFA (\%) & $24.1 \pm 0.2$ & $26.0 \pm 0.4$ & 0.001 & $41.0 \pm 0.4$ & $40.84 \pm 0.08$ & 0.366 & $31.3 \pm 0.2$ & $33.4 \pm 0.5$ & $<0.001$ \\
\hline MUFA (\%) & $75.1 \pm 0.2$ & $73.1 \pm 0.5$ & 0.001 & $26.6 \pm 0.1$ & $21.23 \pm 0.04$ & $<0.001$ & $55.0 \pm 0.6$ & $49.0 \pm 0.1$ & $<0.001$ \\
\hline PUFA (\%) & $0.86 \pm 0.01$ & $0.89 \pm 0.06$ & 0.299 & $32.4 \pm 0.2$ & $37.9 \pm 0.1$ & $<0.001$ & $14.4 \pm 0.2$ & $17.5 \pm 0.6$ & $<0.001$ \\
\hline$\alpha$-Tocopherol (mg/100 g) & $2.22 \pm 0.02$ & $3.36 \pm 0.01$ & $<0.001$ & $18.90 \pm 0.01$ & $17.22 \pm 0.09$ & $<0.001$ & $3.13 \pm 0.05$ & $4.67 \pm 0.02$ & $<0.001$ \\
\hline$\delta$-Tocopherol (mg/100 g) & $0.48 \pm 0.01$ & $1.48 \pm 0.03$ & $<0.001$ & $2.08 \pm 0.01$ & $2.68 \pm 0.07$ & $<0.001$ & $0.45 \pm 0.04$ & $0.19 \pm 0.01$ & $<0.001$ \\
\hline $\begin{array}{l}\text { Total tocopherols (mg/ } \\
100 \mathrm{~g})\end{array}$ & $2.71 \pm 0.01$ & $4.84 \pm 0.01$ & $<0.001$ & $20.98 \pm 0.01$ & $19.90 \pm 0.01$ & $<0.001$ & $3.58 \pm 0.09$ & $4.86 \pm 0.03$ & $<0.001$ \\
\hline
\end{tabular}

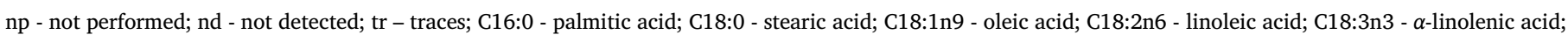
C22:0 - behenic acid; C24:0 - lignoceric acid; SFA - saturated fatty acids; MUFA - monounsaturated fatty acids; PUFA - polyunsaturated fatty acids.

levels were detected in the fruit $(71.91 \pm 0.04$ and $79.6 \pm 0.1 \mathrm{~g} /$ $100 \mathrm{~g} \mathrm{dw})$ and the lowest in the seeds $(38.85 \pm 0.03$ and $41.2 \pm 0.3 \mathrm{~g} / 100 \mathrm{~g} \mathrm{dw}$ in samples from Bissau and Quinhamel, respectively). Proteins rank second with the seeds showing the higher levels $(30.0 \pm 0.6-31.88 \pm 0.08 \mathrm{~g} / 100 \mathrm{~g} \mathrm{dw})$, followed by the flower and the fruit. These last two plant parts also had an interesting content of ash (total minerals), which ranged from $19.83 \pm 0.01$ to $21.3 \pm 0.4 \mathrm{~g} / 100 \mathrm{~g} \mathrm{dw}$. As expected, the seeds had a higher fat content $(\sim 26.3 \mathrm{~g} / 100 \mathrm{~g} \mathrm{dw})$ than the other two edible parts of M. oleifera. In addition, fruits collected in Quinhamel stood out with a significantly higher fat content $(4.3 \pm 0.1 \mathrm{~g} / 100 \mathrm{~g} \mathrm{dw})$ than those collected in Bissau $(2.67 \pm 0.06 \mathrm{~g} / 100 \mathrm{~g} \mathrm{dw})$. The results obtained in this study are slightly lower than those previously reported by Gopalakrishnan, Doriya, and Kumar (2016) and Liang, Wang, Li, Chu, and Sun (2019) for the fat (38.67 and $39.12 \mathrm{~g} / 100 \mathrm{~g}$ ) and protein (35.97 and $40.34 \mathrm{~g} /$ $100 \mathrm{~g}$ ) contents in Indian $M$. oleifera seeds, but were higher for carbohydrates (8.67 and $8.94 \mathrm{~g} / 100 \mathrm{~g}$ ).

Regarding the energy contribution, $100 \mathrm{~g}$ fruit and flower portions provide comparable values $(\sim 390-396 \mathrm{kcal})$, while that of seeds were higher ( $\sim 518-522 \mathrm{kcal})$ mainly due to the fat content.

According to previous reports, $M$. oleifera oil can accelerate wound healing (Liang et al., 2019) and the seed protein fraction has potential to be used in surface water purification due to coagulant effects (Baptista et al., 2017). Therefore, M. oleifera edible parts arise as interesting possibilities for being exploited as raw materials for production of vegetable oil, protein-rich foods and skincare products.

As shown in Table 1, the chromatographic analysis allowed to detect and quantify four free sugars in the studied $M$. oleifera flowers and fruits, namely fructose, glucose, sucrose and trehalose, while just glucose and fructose were found in the seeds. The highest levels were quantified in the fruits (16.7 $\pm 0.1-18.8 \pm 0.2 \mathrm{~g} / 100 \mathrm{~g} \mathrm{fw})$, followed by the flowers $(11.1 \pm 0.1-12.0 \pm 0.2 \mathrm{~g} / 100 \mathrm{~g} \mathrm{fw}$ ) (Fig. S1, Supplementary material) and lastly by the seeds with significantly lower levels $(1.32 \pm 0.09-1.86 \pm 0.06 \mathrm{~g} / 100 \mathrm{~g} \mathrm{fw})$. It was also noted that the quantitative sugar profile of the fruit and flower samples seemed to have been affected by their different origin. These differences could be attributed to edaphoclimatic factors and some biotic conditions that can affect biochemical and physiological processes involved in the plant sugars' production (Ziani et al., 2019). In a previous study, Ziani et al. (2019) identified fructose, glucose and sucrose in $M$. oleifera leaves from Algeria and reported a total free sugars content of $3.82 \mathrm{~g} /$ 100 g dw. Upadhyay, Yadav, Mishra, Sharma, and Purohit (2015) described $L$-arabinose, $D$-galactose, $D$-glucuronic acid, $L$-rhamnose, $D$-mannose, and $D$-xylose as the predominant sugars in the purified whole-gum exudates of $M$. oleifera.

Regarding organic acids, the analysis allowed identifying oxalic, malic, ascorbic, citric, and fumaric acids in flower and fruit samples from both locations (Table 1). Citric and malic acids were the major compounds, while just traces of fumaric acid were detected. Fruits collected in Bissau contained a higher level of ascorbic acid $(0.65 \pm 0.02 \mathrm{~g} / 100 \mathrm{~g} \mathrm{fw})$ than those from Quinhamel or the flower samples. The total organic acid contents ranged from $4.71 \pm 0.02-$ $5.75 \pm 0.02 \mathrm{~g} / 100 \mathrm{~g} \mathrm{fw}$ in fruits to $5.85 \pm 0.01-6.42 \pm 0.01 \mathrm{~g} /$ $100 \mathrm{~g} \mathrm{fw}$ in flowers. In $M$. oleifera seeds, $\sim 10.5 \mathrm{~g} / 100 \mathrm{~g}$ fw of oxalic acid 
were quantified (Table 1), about twice the total content of organic acids found in the other two parts of the plant. Traces of fumaric acid were also detected. It is known that plant foods with a high oxalic acid concentration should be consumed moderately, because the high intake of oxalates may promote the formation of kidney stones, irritation of the intestinal mucosa, and also interferes with calcium absorption (Iyda, Fernandes, Ferreira et al., 2019). To the best of the authors' knowledge, no data are available in the literature regarding the organic acid composition of $M$. oleifera seeds, flowers or fruits. In leaves, Ziani et al. (2019) already reported oxalic, malic and ascorbic acids.

The main fatty acids identified in the studied $M$. oleifera edible parts are also presented in Table 1, while the detailed profiles are shown in Table S1 provided in Supplementary Material. Twenty-one fatty acids were identified in the fruit and flower lipid fractions, while just 14 were detected in the seed samples. The flower lipid fraction was mainly composed by unsaturated fatty acid (SFA; $\sim 41 \%$, due to the contribution of C16:0, C22:0 and C18:0), followed by polyunsaturated fatty acids (PUFA; $32.4 \pm 0.2-37.9 \pm 0.1 \%$ ), namely $\alpha$-linolenic (C18:3n3) and linoleic (C18:2n6) acids. M. oleifera fruits were abundant in monounsaturated fatty acids (MUFA; $49.0 \pm 0.1-55.0 \pm 0.6 \%$ ), particularly those collected in Quinhamel homegardens, due to the high contents of oleic acid (C18:1n9), followed by SFA (31.3 $\pm 0.2-$ $33.4 \pm 0.5 \%$ ), which predominated in the fruit samples from Bissau, given the high levels of palmitic (C16:0), behenic (C22:0) and stearic (C18:0) acids. MUFA also predominated in the seed samples (73.1 $\pm 0.5-75.1 \pm 0.2 \%)$, mostly C18:1n9 but also minor levels of eicosenoic (C20:1) and palmitoleic (C16:1) acids. The SFA C16:0 and C22:0 were also detected in this plant part. In a previous work, Zheng, Wu, Peng, and Zhang (2019) studied the effects of soil drenching and foliar spraying of boron on $M$. oleifera seed oil quality and reported C18:1 levels ranging from 64.24 to $71.17 \%$, a result comparable to that obtained in the present study $(69.44 \pm 0.4$ and $71.6 \pm 0.2 \%$ for seeds from Bissau and Quinhamel, respectively). The lipid composition of $M$. oleifera seeds is greater than that of soybean, which makes it nutritionally important and the refined seed oil is acceptable to substitute the olive oil because of the presence of all the essential fatty acids in it (Singh et al., 2020).

The tocopherols composition of the studied M. oleifera edible parts is shown in Table 1 , where it can be seen that $\alpha$-tocopherol was the prevalent isoform in all samples, followed by $\delta$-tocopherol. The flower samples showed the highest $\alpha$-tocopherol concentrations, ranging from $17.22 \pm 0.09$ to $18.90 \pm 0.01 \mathrm{mg} / 100 \mathrm{~g} \mathrm{dw}$ (HPLC profile in Fig. S2, Supplementary material). Fruit and seed samples revealed a total content of tocopherols ranging from $2.71 \pm 0.01$ to $4.86 \pm 0.03 \mathrm{~g} / 100 \mathrm{~g}$ $\mathrm{dw}$ and the samples collected in Bissau showed higher levels of these lipophilic antioxidants. Singh et al. (2020) reported that tocopherols together with ascorbic acid, carotenoids and flavonoids are antioxidants found in $M$. oleifera with the ability to eliminate reactive oxygen species.

\subsection{Polyphenols compositions of M. oleifera hydroethanolic and aqueous extracts}

Data on the chromatographic characteristics (retention time, UV-Vis spectra in the maximum absorption, molecular ion, and main $\mathrm{MS}^{2}$ fragments) and tentative identification of the phenolic compounds found in the hydroethanolic, infused and decocted extracts of M. oleifera are described in Table 2. Twenty-four phenolic compounds were found, being 19 glycosylated flavonol derivatives, 3 phenolic acids, and 2 flavan-3-ols. The phenolic composition of $M$. oleifera has been extensively studied by other authors (Makita, Chimuka, Steenkamp, Cukrowska, \& Madala, 2016; Nouman et al., 2016; Ramabulana et al., 2016; Ziani et al., 2019); however, there are many compounds identified in the present work that, to the best of the author's knowledge, have never been previously identified in $M$. oleifera. Peaks 3, 6, 13, 14, $15,18,20,21$, and 22 were identified as $(+)$-catechin, (-)-epicatechin,
quercetin-3-O-rutinoside, apigenin-6- $C$-glucoside, quercetin-3-O-glucoside, kaempferol-3-O-rutinoside, isorhamnetin-3-O-rutinoside, kampferol-3-O-glucoside, and isorhamnetin-3-O-glucoside, respectively, by comparing their retention time, UV-Vis spectra, and mass fragmentation patterns with those of the available commercial standards. Only three phenolic acids were tentatively identified, peaks $\mathbf{1} / \mathbf{2}\left([\mathrm{M}-\mathrm{H}]^{-}\right.$at $\mathrm{m} / \mathrm{z} 337)$ and $4\left([\mathrm{M}-\mathrm{H}]^{-}\right.$at $\left.\mathrm{m} / \mathrm{z} 367\right)$, as cis/trans 3-O-p-coumaroylquinic acid and 3-O-feruloyquinic acid, respectively. Peak 1 presented a base peak at $m / z 191$ (quinic acid) along with a peak at $m / z$ 163 (corresponding to the $p$-coumaroyl acid moiety); peak 2 presented the same chromatographic behaviour, leading to the respective identification of the cis and trans isomers of $p$-coumaroylquinic acid. These peaks (1/2 and 4) have been previously identified in the foliar parts of M. oleifera from South Africa, after being exposed to certain levels of radiation (Ramabulana et al., 2016).

The flavonoid was, without any doubt, the most abundant group of phenolic compounds identified in studied $M$. oleifera samples, with glycosylated derivatives of quercetin having a superior numerical expression to any other identified flavonoid aglycone. Peaks $10\left([\mathrm{M}-\mathrm{H}]^{-}\right.$ at $m / z 625), 16\left([\mathrm{M}-\mathrm{H}]^{-}\right.$at $\left.m / z 505\right)$, and $17 / 19\left([\mathrm{M}-\mathrm{H}]^{-}\right.$at $m / z$ 549 ), tentatively identified as quercetin- $O$-dihexoside, quercetin- $O$ acetylhexoside and quercetin-malonylhexoside, respectively, have been previously identified in the leaves of M. oleifera from South Africa (Ramabulana et al., 2016), Pakistan (Nouman et al., 2016), and Namibia (Makita et al., 2016). Peak 5 presented a pseudomolecular ion $[\mathrm{M}-\mathrm{H}]^{-}$at $m / z 711$, and $\mathrm{MS}^{2}$ fragments at $m / z 667$ (loss of $44 \mathrm{u}$, carboxyl radical), $m / z 505$ (loss of sinapoylradical), $m / z 463$ (loss of sinapoyl and acetyl radicals), and $m / z 301$ (quercetin aglycone), which allowed the tentative identification as quercetin-acetylglucoside-sinapic acid. This peak has not been identified in $M$. oleifera samples, so its tentative identification was performed following the previously described by Medina et al. (2017) in Passiflora edulis shell, without numbering the oxygen atoms and radicals position since it was not possible to compare the abundance of each fragment. Peak 11, also a glycosylated derivative of quercetin, presented a pseudomolecular ion $[\mathrm{M}-\mathrm{H}]^{-}$at $m / z 595$, and $\mathrm{MS}^{2}$ fragments at $\mathrm{m} / \mathrm{z} 463$ and $\mathrm{m} / \mathrm{z} 301$, corresponding to the loss of a pentosyl and hexosyl moieties, respectively. As peak 5, peak $\mathbf{1 1}$ was not previously identified in M. oleifera samples, so its tentative identification followed the previously described by Barros et al. (2013) in Cistus ladanifer. The second major flavonoid group was that of $C$-glycosylated apigenin derivatives, represented by peaks $7\left([\mathrm{M}-\mathrm{H}]^{-}\right.$at $\left.m / z 593\right), 9\left([\mathrm{M}-\mathrm{H}]^{-}\right.$at $\left.m / z 593\right)$ and $12\left([\mathrm{M}-\mathrm{H}]^{-}\right.$at $\left.m / z 431\right)$, tentatively identified as apigenin-6,8-C-diglucoside, apigenin- $O$-hexoside- $C$-hexoside, and apigenin- $C$-hexoside, respectively, following the previously described by Truchado, Vit, Ferreres, and Tomas-Barberan (2011) and Qiao et al. (2011), being previously identified similar compounds in $M$. oleifera leaves (Nouman et al., 2016; Ramabulana et al., 2016). Kaempferol derivatives were also found; peak 8, tentatively identified as kaempferol-O-malonylhexoside, was previously reported in $M$. oleifera leaf samples by Makita et al. (2016), and peak 23, presenting a pseudomolecular ion $[\mathrm{M}-\mathrm{H}]^{-}$at $m / z 695$, was tentatively identified as kaempferol-O-malonyldihexoside, following the previously described by Sánchez-Salcedo et al. (2016) in Morus spp. leaves (to the best of the authors' knowledge, this peak as not been described previously in M. oleifera). Finally, peak 24, tentatively identified as isorhamnetin-O-malonylhexoside, was previously described in M. oleifera leaves by Ziani et al. (2019).

Data on the quantification of the phenolic compounds present in $M$. oleifera edible parts are presented in Table 3. The profile of phenolic compounds present in each group of $M$. oleifera samples was very different, quantitatively but also qualitatively, with very few similar compounds between samples, which could be explained by the different physiological function of the studied plant parts and/or different microenvironmental conditions in each sampling site, namely a wetter and more shaded environment at the Ponta Romana homegarden.

The hydroethanolic extracts prepared with flowers from Bissau 
Table 2

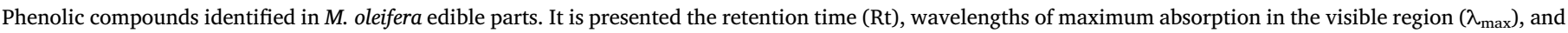
mass spectral data.

\begin{tabular}{|c|c|c|c|c|c|c|}
\hline Peak & Rt (min) & $\lambda_{\max (\mathrm{nm})}$ & {$[\mathrm{M}-\mathrm{H}]^{-}(m / z)$} & $\operatorname{MS}^{2}(m / z)$ & Tentative identification & $\begin{array}{l}\text { Reference/method used for } \\
\text { quantification }\end{array}$ \\
\hline 1 & 6.19 & 311 & 337 & 191(8), 173(6), 163(100), 153(3), 119(5) & cis 3-O-p-Coumaroylquinic acid & Ramabulana et al. (2016) \\
\hline 2 & 7.09 & 311 & 337 & 191(8), 173(6), 163(100), 153(3), 119(5) & trans 3-O-p-Coumaroylquinic acid & Ramabulana et al. (2016) \\
\hline 3 & 7.11 & 280 & 289 & $245(25), 203(10), 137(31)$ & $(+)$-Catechin & Standard compound \\
\hline 4 & 7.16 & 323 & 367 & 193(100), 191(5), 173(5), 149(3), 134(8) & 3-O-Feruloyquinic acid & Ramabulana et al. (2016) \\
\hline 5 & 8.6 & $256 / 268 / 351$ & 711 & 667(52), 505(100), 463(37), 301(21) & Quercetin- $O$-acetylglucosyl-sinapic acid & Medina et al. (2017) \\
\hline 6 & 9.57 & 280 & 289 & 245(100), 205(52), 151(29), 137(37) & (-)-Epicatechin & Standard compound \\
\hline 7 & 9.97 & 322 & 593 & $\begin{array}{l}\text { 575(11), 503(24), 473(100), } 383(12), \\
353(27)\end{array}$ & Apigenin-6,8-C-diglucoside & Truchado et al. (2011) \\
\hline 8 & 12.59 & 342 & 695 & 651(53), 489(100), 447(28), 285(41) & Kaempferol-O-malonyldihexoside & Sánchez-Salcedo et al. (2016) \\
\hline 9 & 13.55 & 337 & 593 & 473(35), 431(100), 353(5), 311(62), 283(5) & Apigenin- $O$-hexoside- $C$-hexoside & Qiao et al. (2011) \\
\hline 10 & 15.05 & 359 & 625 & $301(100)$ & Quercetin-O-dihexoside & Nouman et al. (2016) \\
\hline 11 & 15.98 & 350 & 595 & 463(31), 301(100) & Quercetin- $O$-pentoside- $O$-hexoside & Barros et al. (2013) \\
\hline 12 & 16.51 & 334 & 431 & 413(5), 341(6), 311(100) & Apigenin- $C$-hexoside & Nouman et al. (2016) \\
\hline 13 & 17.77 & 354 & 609 & $301(100)$ & Quercetin-3-O-rutinoside & Standard compound \\
\hline 14 & 18.35 & 337 & 431 & 413(7), 341(26), 311(100) & Apigenin-6-C-glucoside & Standard compound \\
\hline 15 & 18.91 & 353 & 463 & $301(100)$ & Quercetin-3-O-glucoside & Standard compound \\
\hline 16 & 20.19 & 353 & 505 & $463(30), 301(100)$ & Quercetin-O-acetylhexoside & Ramabulana et al. (2016) \\
\hline 17 & 20.21 & 352 & 549 & $505(12), 463(22), 301(100)$ & Quercetin- $O$-malonylhexoside & Makita et al. (2016) \\
\hline 18 & 21.06 & 347 & 593 & $285(100)$ & Kaempferol-3-O-rutinoside & Standard compound \\
\hline 19 & 22.06 & 350 & 549 & 505(72), 463(27), 301(100) & Quercetin- $O$-malonylhexoside & Makita et al. (2016) \\
\hline 20 & 22.07 & 353 & 623 & $315(100)$ & Isorhamnetin-3-O-rutinoside & Standard compound \\
\hline 21 & 22.39 & 346 & 447 & $285(100)$ & Kampferol-3-O-glucoside & Standard compound \\
\hline 22 & 23.36 & 352 & 477 & $315(100)$ & Isorhamnetin-3-O-glucoside & Standard compound \\
\hline 23 & 24.62 & 346 & 533 & $489(89), 447(10), 285(100)$ & Kaempferol-O-malonylhexoside & Makita et al. (2016) \\
\hline 24 & 25.92 & 353 & 563 & 519(88), 315(100) & Isorhamnetin- $O$-malonylhexoside & Ziani et al. (2019) \\
\hline
\end{tabular}

presented the highest total concentration of phenolic compounds, $14.7 \pm 0.1 \mathrm{mg} / \mathrm{g}$ of extract, followed by the Quinhamel flower hydroethanolic extract, with $13.8 \pm 0.1 \mathrm{mg} / \mathrm{g}$ of extract. The seed samples were the only ones presenting flavan-3-ols derivatives, representing the major group of phenolics within this group. Another information that is important to highlight is the fact that the decoction prepared with the Quinhamel fruit sample had no phenolic compounds. Although an aqueous preparation such as decoction can lead to the thermal degradation of compounds, the absence of compounds may be related to the sample itself, since the hydroethanolic extract of this sample also had the lowest total concentration of phenolic compounds $(0.765 \pm 0.001 \mathrm{mg} / \mathrm{g}$ extract) within the corresponding group of samples.

Despite the very different phenolic profile, the most abundant phenolic compound (apart from seeds samples) was peak 1 (cis 3-O-pcoumaroylquinic acid), which did not produce an effect of higher concentration of phenolic acids, since it was the group of flavonoids that stood out (less in the Quinhamel flower hydroethanolic extract). These results are in accordance with the described by Ziani et al. (2019) and Nouman et al. (2016) in M. oleifera leaves, in which they revealed total concentrations of flavonoids of up to $30 \mathrm{mg} / \mathrm{g}$ extract and $2.98 \mathrm{mg} / \mathrm{g}$ extract, respectively.

\subsection{Bioactive properties of M. Oleifera hydroethanolic and aqueous extracts}

To evaluate the bioactive properties of the different $M$. oleifera edible parts, hydroethanolic, infused and decocted extracts were prepared according to traditional uses and applications. Fruits are traditionally prepared as a culinary vegetable, stewed in curries and soups. In India and Bangladesh, fruits are usually prepared by boiling pods to the desired level of tenderness in a mixture of coconut milk and spices (Lim, 2014). Therefore, only hydroethanolic and decocted extracts were prepared in this study with the fruit samples. On the other hand, seeds and flowers were used to prepare hydroethanolic, infused and decocted extracts. Traditionally, mature seeds are fried and eaten like peanuts in Nigeria and added to sauces for their bitter taste. In Pakistan are used to prepare M. oleifera seed tea infusions (Ilyas et al., 2015) and in India seed decoctions (Dhakar et al., 2011). The flowers are cooked and consumed either mixed with other foods or fried in batter, butter or oil. In West Bengal and Bangladesh, these are usually cooked with green peas and potato, while in Africa are eaten as a vegetable, added to sauces or used to make infusions (Lim, 2014).

\subsubsection{Antioxidant activity}

Two in vitro cell-based assays were used to measure the antioxidant activity of the hydroethanolic, infused and decocted extracts of the different $M$. oleifera parts (Table 4). These assays evaluate the extract ability to inhibit the formation of thiobarbituric acid reactive substances (TBARS) and the oxidative haemolysis (OxHLIA) using porcine brain tissues and erythrocytes as oxidizable biological substrates, respectively. As can be observed in Table 4, in the TBARS assay, significant differences were found between the three plant parts and between the extraction methods. The hydroethanolic extracts showed the lowest $\mathrm{EC}_{50}$ values, thus translating a greater capacity to inhibit the TBARS formation than the aqueous extracts.

This result could be justified by the greater efficiency of the hydroethanolic mixture in extracting phenolic compounds and other antioxidants (Padayachee \& Baijnath, 2020). In the OxHLIA assay, the sheep erythrocytes were subjected to the haemolytic action of both hydrophilic and lipophilic radicals generated in in vitro by the thermal decomposition of the free-radical initiator AAPH and as a consequence of the initial attack, respectively. By observing the data presented in Table 4, it can be noticed that infusions prepared with seed and flower samples from Bissau showed the best results, with $\mathrm{IC}_{50}$ values lower than those of the trolox, the water-soluble analog of vitamin $\mathrm{E}$ used as a positive control. Interestingly, the hydroethanolic extracts did not show any antihemolytic effect. In a previous study, Pakade, Cukrowska, and Chimuka (2013) compared the antioxidant activity of $M$. oleifera leaves and flowers to that of several vegetables from South Africa, including spinach, cauliflower, broccoli, cabbage, and peas, and reported a total flavonoid content in $M$. oleifera three times higher than that quantified in the others plant foods, thus concluded that M. oleifera is a better source of antioxidants. 


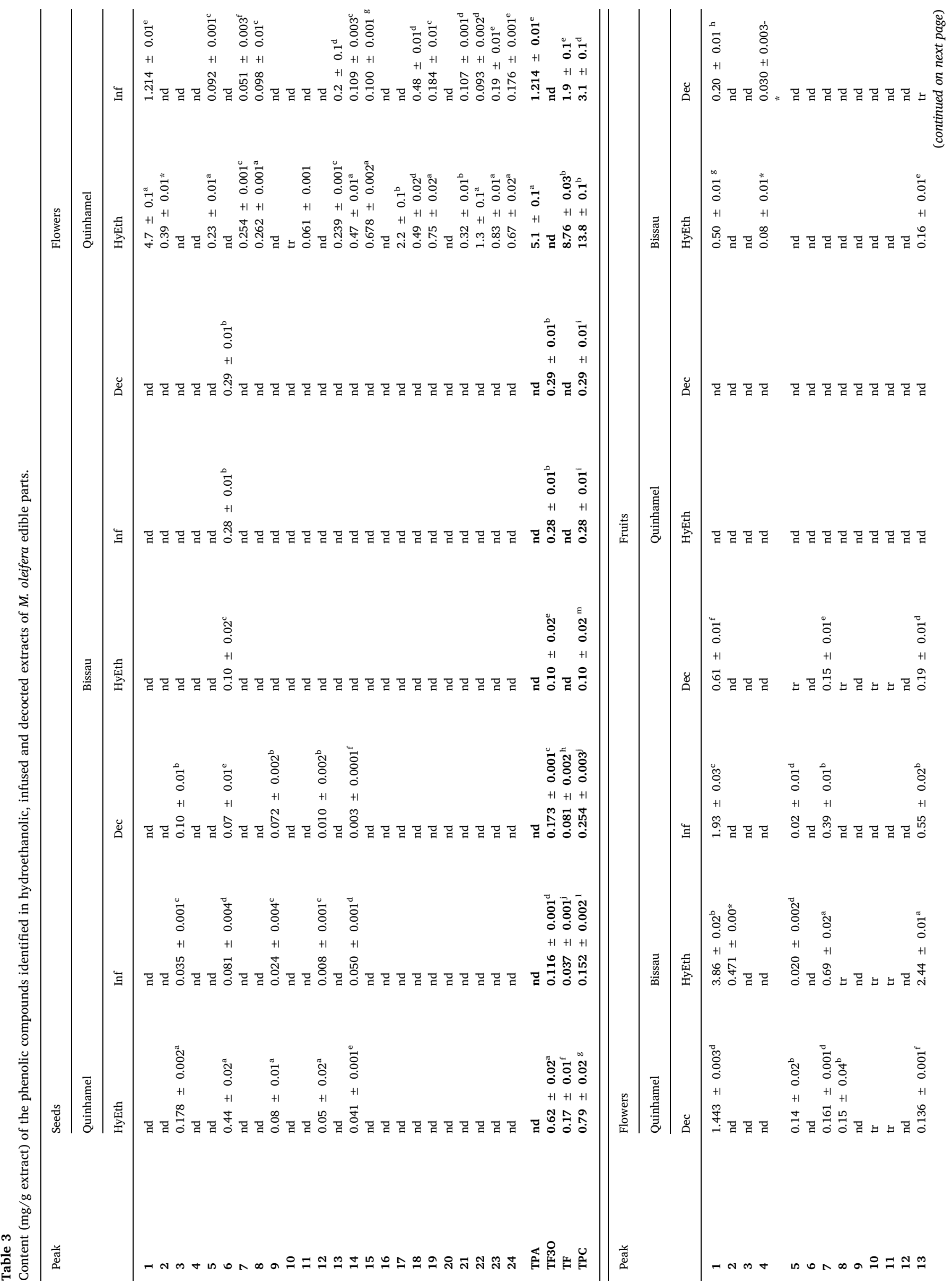




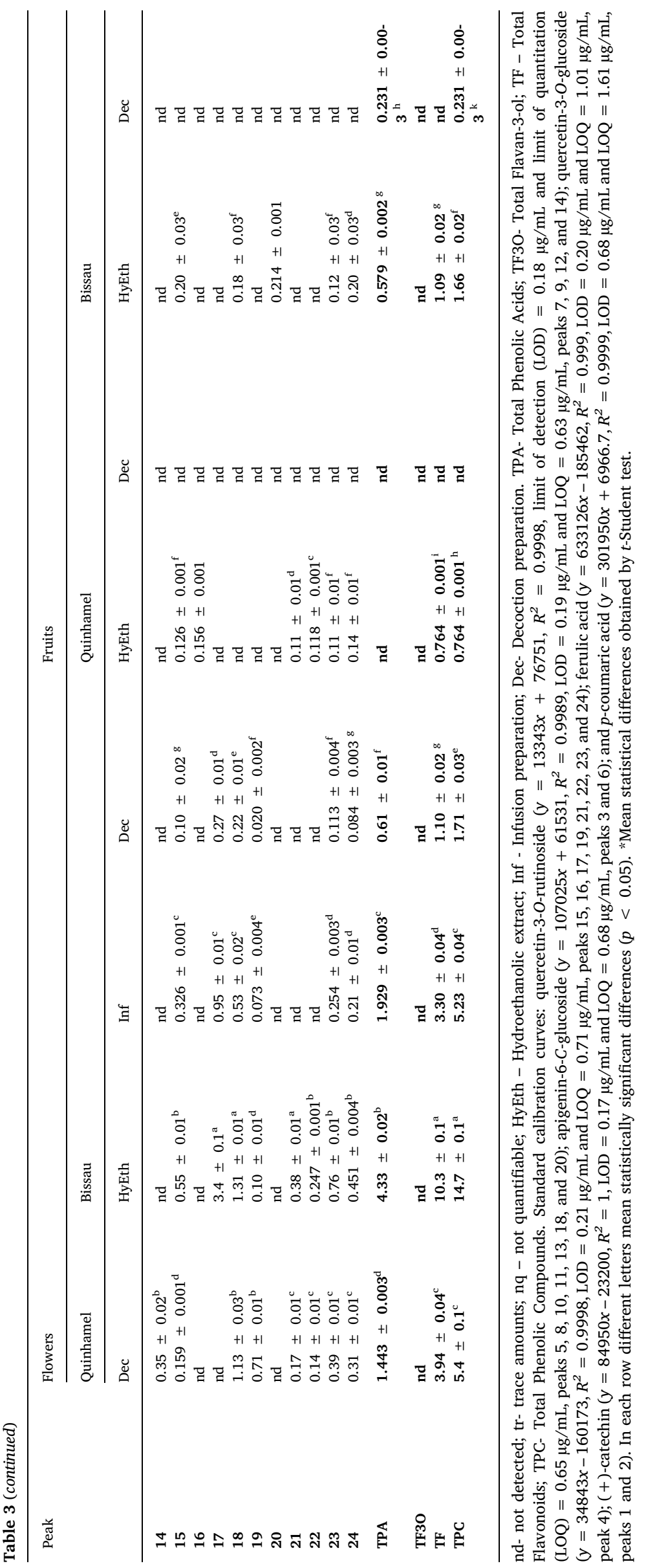




\subsubsection{NO-production inhibition activity}

The NO-production inhibition (or anti-inflammatory) activity of the tested $M$. oleifera extracts was assessed based on the NO-production inhibition activity and the results are presented in Table 4 . The extracts prepared with the seed samples from both locations were able to reduce the production of NO by LPS-stimulated murine macrophages. This result followed the same trend observed for the TBARS formation inhibition assay, with the hydroethanolic preparations showing the best results. However, flower and fruit extracts did not reveal anti-inflammatory activity at the tested concentrations. In previous studies, Minaiyan, Asghari, Taheri, Saeidi, and Nasr-Esfahani (2014) showed that hydroalcoholic seed extracts are effective in the treatment of experimental colitis and associated this effect with the major bioactive biophenols and flavonoids (Minaiyan et al., 2014). In turn, JajaChimedza et al. (2017) connected the anti-inflammatory and antioxidant properties of $M$. oleifera seeds to the presence of isothiocyanates. Accordingly Padayachee and Baijnath (2020), infusions of M. oleifera leaves, seeds, flowers, roots, and bark display anti-inflammatory activity. Alhakmani, Kumar, and Khan (2013) also attributed anti-inflammatory effects to the $M$. oleifera flower extract, which supports the traditional use of this preparation in Oman and other Asian countries.

\subsubsection{Cytotoxicity to tumour and non-tumour cells}

Considering the described uses of the different parts of $M$. oleifera in traditional medicine, the prepared extracts were also tested for their cytotoxicity for tumour and non-tumour cell lines. The performed sulforhodamine B assay allows to evaluate the effect of the extracts on cell proliferation (Ziani et al., 2019). Therefore, $\mathrm{GI}_{50}$ values translate the extract concentration providing $50 \%$ of cell growth inhibition. As presented in Table 4, the hydroethanolic extracts of seed and flower samples originated the lower $\mathrm{GI}_{50}$ values, thus translating a higher activity than the aqueous extracts against HeLa (cervical), HepG2 (hepatocellular), MCF-7 (breast) and NCI-H460 (lung) tumour cells. Among the hydroethanolic extracts, those prepared with seeds were more effective against the HepG2 cell line, regardless of the geographic origin of the samples (with $\mathrm{GI}_{50}$ of $82 \pm 5-95 \pm 2 \mu \mathrm{g} / \mathrm{mL}$ ), while those prepared with flowers were more cytotoxic to breast MCF-7 cells (with $\mathrm{GI}_{50}$ of $163 \pm 5-187 \pm 10 \mu \mathrm{g} / \mathrm{mL}$ ). For seeds, the decoctions proved to be the least cytotoxic preparations for the tested cell lines (given the higher $\mathrm{GI}_{50}$ values), which is in line with the results obtained with the OxHLIA assay (where they also had the highest $\mathrm{IC}_{50}$ values). The aqueous flower extracts were not cytotoxic at the tested concentrations, nor any of those prepared with the fruits.

In previous studies, Jung (2014) found that aqueous M. oleifera leaf extracts are able to reduce the proliferation and invasion of cancer cells by inducing apoptosis, inhibiting the tumour cell growth and decreasing the level of internal reactive oxygen species in human lung cancer cells. Al-Asmari et al. (2015) evaluated the anticancer properties of $M$. oleifera leaf, bark and seed extracts against breast (MDA-MB-231) and colorectal (HCT-8) cancer cells and obtained remarkable anticancer activities with the leaf and bark extracts, while the seed extract showed less activity. It has also been reported that the flavonoids quercetin and kaempferol present in $M$. oleifera extracts may act as potential chemopreventive agents, being able to reduce the proliferation of human carcinoma through the induction of in vitro apoptosis (Padayachee \& Baijnath, 2020). In addition, the presence of these and other antioxidants in $M$. oleifera allows to reduce oxidative stress and, consequently, help prevent the development of cancer. Among the metabolites with antioxidant activity found in $M$. oleifera are flavonoids, phenolic acids, saponins, tannins, $\beta$-carotene, and terpenoids (Singh et al., 2020).

Table 4 also shows that, with the exception of the hydroethanolic seed extracts, no other extract was cytotoxic to the non-tumour PLP2 cells at the tested concentrations. This toxicity of the hydroethanolic seed extracts to porcine liver primary cells may somehow justify the absence of antihemolytic activity in the OxHLIA assay, since the erythrocytes may have been rapidly lysed due to the cytotoxic effect of these hydroalcoholic preparations.

In many countries, $M$. oleifera seed powder is used to purify water on aquaculture farms due to its coagulation properties. Nevertheless, the application of a large amount of this ingredient in aquaculture ponds leads to fish mortality due to the presence of toxic or antinutritional compounds. The seed powder toxicity has already been observed in guppies (Poecilia reticulata), Nile tilapia (Oreochromis niloticus), protozoa (Tetrahymena pyriformis), and bacteria (Escherichia coli) (Kavitha, Ramesh, Kumaran, \& Lakshmi, 2012). Regarding ethanolic and aqueous extracts of both $M$. oleifera fruits and leaves, Luqman, Srivastava, Kumar, Maurya, and Chanda (2011) showed that these are well tolerated by experimental animals without toxicity of the extracts up to a dose of $100 \mathrm{mg} / \mathrm{kg}$ of body weight. The aqueous and hydroethanolic extracts of $M$. oleifera flowers have also been described as having a significant hepatoprotective effect, which may be due to the presence of quercetin, a well-known flavonoid with hepatoprotective activity (Upadhyay et al., 2015). Furthermore, Singh et al. (2020) described that alcoholic and aqueous extracts from flowers and roots of $M$. oleifera act as hepatoprotectors against the effect of acetaminophen (a drug used to treat pain and fever) by decreasing the level of serum enzymatic markers and bilirubin levels.

\subsubsection{Antimicrobial activity}

The results of the antimicrobial activity of $M$. oleifera extracts are presented in Table 5. All the extracts had significant antimicrobial effects against the tested bacteria and fungi. The MIC and MBC values obtained for Bacillus cereus, Staphylococcus aureus, Listeria monocytogenes, and Escherichia coli, as well as for Enterobacter cloacae and Salmonella Typhimurium, were comparable to those of streptomycin and ampicillin, the antibiotics used as positive controls, thus translating a similar bacteriostatic and bactericidal activity. In general, decoctions were the most effective preparations against the tested bacteria and, in the case of seeds, it is also worth noting the higher activity of the hydroethanolic and infused extracts prepared with seeds from Quinhamel and the decocted extracts made with seed from Bissau. The antimicrobial activity of $M$. oleifera leaf, root, bark and seed extracts against bacteria, yeasts, dermatophytes, and helminths pathogenic to human was previously investigated by Upadhyay et al. (2015), which verified that the seed aqueous extract inhibits the growth of Pseudomonas aeruginosa and $S$. aureus. According to previous reports, the antimicrobial activity of $M$. oleifera seed powder is conferred by a short cationic protein (Singh et al., 2020), as well as by saponins, tannins, phenolics, and alkaloids (Padayachee \& Baijnath, 2020).

The antifungal activity of the tested $M$. oleifera extracts resulted in MIC and MBC values lower or similar to those of the positive controls ketoconazole and bifonazole (Table 5). The antifungal activity of aqueous leaf extracts of $M$. oleifera was previously confirmed by Padayachee and Baijnath (2020) against Penicillium spp., while the ethanolic extract also inhibited Candida albicans, Penicillium spp., and Mucor spp. The phytochemical screening of this plant part revealed the presence of alkaloids, flavonoids, saponins, terpenoids, steroids, tannins, and cardiac glycosides, which may act as natural antimicrobials (Padayachee \& Baijnath, 2020).

\section{Conclusion}

The results of the present study highlighted the nutritional quality of $M$. oleifera fruits, seeds and flowers from Bissau and Quinhamel and the bioactive potential of their herbal preparations. These edible and medicinal matrices stood out not only with high nutritional value, but also for their potential to be used in food fortification and in the development of new functional foods, nutraceuticals and pharmaceutical formulations. M. oleifera is a natural resource to be valorised by underprivileged population facing poverty and malnutrition issues, but 


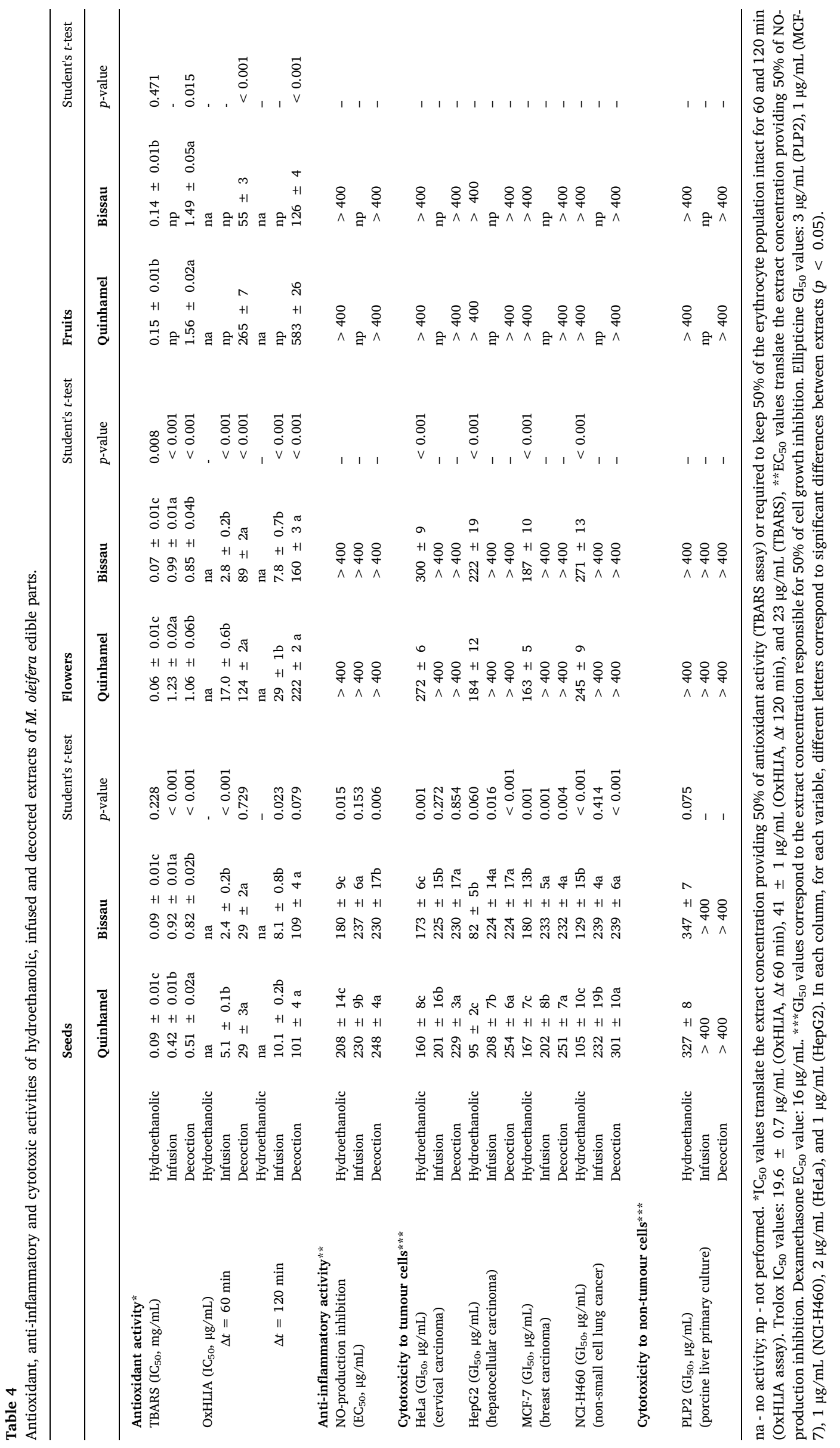


Table 5

Antibacterial and antifungal activity of hydroethanolic, infused and decocted extracts of $M$. oleifera edible parts.

\begin{tabular}{|c|c|c|c|c|c|c|c|c|c|}
\hline & & \multicolumn{2}{|l|}{ Seeds } & \multicolumn{2}{|l|}{ Flowers } & \multicolumn{2}{|l|}{ Fruits } & \multicolumn{2}{|c|}{ Positive controls } \\
\hline & & Quinhamel & Bissau & Bissau & Quinhamel & Quinhamel & Fruits Bissau & Streptomycin & Ampicillin \\
\hline Antibacterial activity $(\mathrm{mg} / \mathrm{mL})$ & & MIC/MBC & $\mathrm{MIC} / \mathrm{MBC}$ & $\mathrm{MIC} / \mathrm{MBC}$ & $\mathrm{MIC} / \mathrm{MBC}$ & MIC/MBC & MIC/MBC & MIC/MBC & $\mathrm{MIC} / \mathrm{MBC}$ \\
\hline \multirow[t]{3}{*}{ B. cereus } & Hydroethanolic & $0.075 / 0.15$ & $0.10 / 0.20$ & $0.10 / 0.20$ & $0.10 / 0.20$ & $0.20 / 0.40$ & $0.20 / 0.40$ & $0.04 / 0.10$ & $0.25 / 0.45$ \\
\hline & Infusion & $0.075 / 0.15$ & $0.60 / 0.90$ & $0.15 / 0.30$ & $0.15 / 0.30$ & np & $\mathrm{np}$ & & \\
\hline & Decoction & $0.075 / 0.15$ & $0.037 / 0.075$ & $0.075 / 0.30$ & $0.075 / 0.30$ & $0.20 / 0.30$ & $0.15 / 0.30$ & & \\
\hline \multirow[t]{3}{*}{ S. aureus } & Hydroethanolic & $0.10 / 0.20$ & $0.25 / 0.50$ & $0.30 / 0.60$ & $0.30 / 0.60$ & $0.20 / 0.40$ & $0.20 / 0.40$ & $0.10 / 0.20$ & $0.25 / 0.40$ \\
\hline & Infusion & $0.15 / 0.30$ & $0.50 / 0.90$ & $0.30 / 0.60$ & $0.45 / 0.60$ & $\mathrm{np}$ & $\mathrm{np}$ & & \\
\hline & Decoction & $0.075 / 0.15$ & $0.037 / 0.075$ & $0.075 / 0.30$ & $0.15 / 0.30$ & $0.20 / 0.30$ & $0.20 / 0.30$ & & \\
\hline \multirow[t]{3}{*}{ L. monocytogenes } & Hydroethanolic & $0.10 / 0.20$ & $0.45 / 0.90$ & $0.10 / 0.20$ & $0.10 / 0.20$ & $0.10 / 0.20$ & $0.10 / 0.20$ & $0.20 / 0.30$ & $0.40 / 0.50$ \\
\hline & Infusion & $0.10 / 0.15$ & $0.60 / 0.90$ & $0.15 / 0.30$ & $0.15 / 0.30$ & np & $\mathrm{np}$ & & \\
\hline & Decoction & $0.075 / 0.15$ & $0.037 / 0.075$ & $0.05 / 0.10$ & $0.20 / 0.30$ & $0.20 / 0.30$ & $0.075 / 0.15$ & & \\
\hline \multirow[t]{3}{*}{ E. coli } & Hydroethanolic & $0.10 / 0.20$ & $0.10 / 0.20$ & $0.075 / 0.15$ & $0.10 / 0.20$ & $0.10 / 0.25$ & $0.10 / 0.20$ & $0.20 / 0.30$ & $0.40 / 0.50$ \\
\hline & Infusion & $0.10 / 0.15$ & $0.15 / 0.30$ & $0.075 / 0.15$ & $0.10 / 0.15$ & np & np & & \\
\hline & Decoction & $0.05 / 0.15$ & $0.037 / 0.075$ & $0.10 / 0.15$ & $0.20 / 0.30$ & $0.075 / 0.15$ & $0.10 / 0.15$ & & \\
\hline \multirow[t]{3}{*}{ E. cloacae } & Hydroethanolic & $0.10 / 0.20$ & $0.30 / 0.60$ & $0.30 / 0.60$ & $0.50 / 1.00$ & $0.30 / 0.60$ & $0.25 / 0.50$ & $0.20 / 0.30$ & $0.25 / 0.50$ \\
\hline & Infusion & $0.15 / 0.30$ & $0.90 / 1.20$ & $0.30 / 0.60$ & $0.40 / 0.90$ & np & $\mathrm{np}$ & & \\
\hline & Decoction & $0.05 / 0.15$ & $0.037 / 0.075$ & $0.075 / 0.15$ & $0.20 / 0.30$ & $0.075 / 0.15$ & $0.10 / 0.15$ & & \\
\hline \multirow[t]{3}{*}{ S. Typhimurium } & Hydroethanolic & $0.10 / 0.20$ & $0.30 / 0.60$ & $0.10 / 0.15$ & $0.30 / 0.60$ & $0.25 / 0.50$ & $0.15 / 0.30$ & $0.20 / 0.30$ & $0.75 / 1.20$ \\
\hline & Infusion & $0.15 / 0.30$ & $0.30 / 0.90$ & $0.15 / 0.30$ & $0.45 / 0.60$ & & & & \\
\hline & Decoction & $0.037 / 0.075$ & $0.018 / 0.075$ & $0.25 / 0.60$ & $0.25 / 0.60$ & $0.20 / 0.30$ & $0.075 / 0.15$ & & \\
\hline \multirow[t]{2}{*}{ Antifungal activity $(\mathrm{mg} / \mathrm{mL})$} & & & & & & & & Ketoconazole & Bifonazole \\
\hline & MIC/MFC & MIC/MFC & & MIC/MFC & MIC/MFC & MIC/MFC & MIC/MFC & MIC/MFC & MIC/MFC \\
\hline \multirow[t]{3}{*}{ A. fumigatus } & Hydroethanolic & $0.075 / 0.15$ & $0.05 / 0.075$ & $0.25 / 0.50$ & $0.20 / 0.40$ & $0.10 / 0.20$ & $0.10 / 0.20$ & $0.25 / 0.50$ & $0.15 / 0.20$ \\
\hline & Infusion & $0.075 / 0.15$ & $0.05 / 0.10$ & $0.30 / 0.60$ & $0.075 / 0.15$ & $\mathrm{np}$ & $\mathrm{np}$ & & \\
\hline & Decoction & $0.018 / 0.037$ & $0.075 / 0.15$ & $0.018 / 0.037$ & $0.075 / 0.15$ & $0.075 / 0.15$ & $0.075 / 0.15$ & & \\
\hline \multirow[t]{3}{*}{ A. ochraceus } & Hydroethanolic & $0.075 / 0.15$ & $0.075 / 0.15$ & $0.015 / 0.030$ & $0.075 / 0.15$ & $0.10 / 0.20$ & $0.10 / 0.20$ & $0.20 / 0.50$ & $0.10 / 0.20$ \\
\hline & Infusion & $0.037 / 0.075$ & $0.037 / 0.075$ & $0.075 / 0.15$ & $0.037 / 0.075$ & $\mathrm{np}$ & $\mathrm{np}$ & & \\
\hline & Decoction & $0.037 / 0.075$ & $0.037 / 0.075$ & $0.018 / 0.037$ & $0.037 / 0.75$ & $0.037 / 0.075$ & $0.037 / 0.075$ & & \\
\hline \multirow[t]{3}{*}{ A. niger } & Hydroethanolic & $0.037 / 0.075$ & $0.037 / 0.075$ & $0.15 / 0.30$ & $0.15 / 0.30$ & $0.30 / 0.60$ & $0.30 / 0.60$ & $0.20 / 0.50$ & $0.15 / 0.20$ \\
\hline & Infusion & $0.037 / 0.075$ & $0.037 / 0.075$ & $0.15 / 0.30$ & $0.15 / 0.30$ & np & np & & \\
\hline & Decoction & $0.075 / 0.15$ & $0.075 / 0.15$ & $0.075 / 0.15$ & $0.037 / 0.075$ & $0.075 / 0.15$ & $0.037 / 0.075$ & & \\
\hline \multirow[t]{3}{*}{ P. funiculosum } & Hydroethanolic & $0.037 / 0.075$ & $0.037 / 0.075$ & $0.037 / 0.075$ & $0.15 / 0.30$ & $0.15 / 0.30$ & $0.15 / 0.30$ & $0.20 / 0.50$ & $0.20 / 0.25$ \\
\hline & Infusion & $0.037 / 0.075$ & $0.075 / 0.15$ & $0.05 / 0.10$ & $0.15 / 0.30$ & $\mathrm{np}$ & $\mathrm{np}$ & & \\
\hline & Decoction & $0.037 / 0.075$ & $0.037 / 0.075$ & $0.037 / 0.075$ & $0.075 / 0.15$ & $0.075 / 0.30$ & $0.037 / 0.075$ & & \\
\hline \multirow[t]{3}{*}{ P. ochrochloron } & Hydroethanolic & $0.037 / 0.075$ & $0.037 / 0.075$ & $0.10 / 0.20$ & $0.15 / 0.60$ & $0.45 / 0.90$ & $0.60 / 1.20$ & $2.50 / 3.50$ & $0.20 / 0.25$ \\
\hline & Infusion & $0.10 / 0.15$ & $0.15 / 0.30$ & $0.075 / 0.15$ & $0.20 / 0.40$ & $\mathrm{np}$ & np & & \\
\hline & Decoction & $0.075 / 0.15$ & $0.075 / 0.15$ & $0.075 / 0.15$ & $0.30 / 0.45$ & $0.075 / 0.15$ & $0.037 / 0.075$ & & \\
\hline \multirow[t]{3}{*}{ P. aurantioriseum } & Hydroethanolic & $0.037 / 0.075$ & $0.037 / 0.075$ & $0.15 / 0.30$ & $0.30 / 0.60$ & $0.10 / 0.20$ & $0.15 / 0.30$ & $0.20 / 0.30$ & $0.10 / 0.20$ \\
\hline & Infusion & $0.075 / 0.15$ & $0.15 / 0.30$ & $0.075 / 0.15$ & $0.20 / 0.40$ & $\mathrm{np}$ & np & & \\
\hline & Decoction & $0.075 / 0.15$ & $0.075 / 0.15$ & $0.037 / 0.15$ & $0.30 / 0.45$ & $0.075 / 0.15$ & $0.037 / 0.15$ & & \\
\hline
\end{tabular}

MIC - minimum inhibitory concentrations; MBC - minimum bactericidal concentration; MFC - minimum fungicidal concentration; np - not performed.

also by other stockholders, specifically in underdeveloped and developing nations that have an insufficient technical resources.

\section{CRediT authorship contribution statement}

Ângela Fernandes: Methodology, Software, Validation, Investigation, Data curation, Writing - original draft, Writing - review \& editing, Funding acquisition. Aducabe Bancessi: Writing - original draft. José Pinela: Software, Data curation, Writing - original draft, Writing - review \& editing. Maria Inês Dias: Methodology, Software, Validation, Investigation, Data curation, Writing - original draft, Funding acquisition. Ângela Liberal: Methodology. Ricardo C. Calhelha: Methodology, Investigation, Data curation, Funding acquisition. Ana Ćirić: Methodology. Marina Soković: Supervision. Luís Catarino: Conceptualization, Visualization, Supervision. Isabel C.F.R. Ferreira: Writing - review \& editing, Supervision, Project administration. Lillian Barros: Conceptualization, Validation, Investigation, Writing - original draft, Writing - review \& editing, Visualization, Supervision, Project administration, Funding acquisition.

\section{Declaration of Competing Interest}

The authors declare that they have no known competing financial interests or personal relationships that could have appeared to influence the work reported in this paper.

\section{Acknowledgements}

The authors are grateful to the Foundation for Science and Technology (FCT, Portugal) for financial support through national funds FCT/MCTES to CIMO (UIDB/00690/2020), to cE3c (UIDB/ 00329/2020), and to the A. Bancessi PhD grant (SFRH/BD/135356/ 2017). National funding by FCT, P.I., through the institutional scientific employment program-contract for A. Fernandes, J. Pinela, M.I. Dias, R.C. Calhelha, and L. Barros contracts. This work was funded by FEDER-Interreg España-Portugal programme through the project 0377_Iberphenol_6_E and TRANSCoLAB 0612_TRANS_CO_LAB_2_P, and also by the Ministry of Education, Science and Technological Development of Republic of Serbia (451-03-68/2020-14/200007). 


\section{Appendix A. Supplementary data}

Supplementary data to this article can be found online at https:// doi.org/10.1016/j.foodchem.2020.128229.

\section{References}

Adouni, K., Chahdoura, H., Mosbah, H., Santos-Buelga, C., González-Paramás, A. M., Ciudad-Mulero, M., Fernandes, A., Calhelha, R. C., Morales, P., Flamini, G., Ferreira, I. C. F. R., \& Achour, L. (2018). Revalorization of wild Asparagus stipularis Forssk. as a traditional vegetable with nutritional and functional properties. Food and Function, 9, 1578.

Ajibade, T. O., Arowolo, R., \& Olayemi, F. O. (2013). Phytochemical screening and toxicity studies on the methanol extract of the seeds of Moringa oleifera. Journal of Complementary and Integrative Medicine, 10.

Al-Asmari, A. K., Albalawi, S. M., Athar, M. T., Khan, A. Q., Al-Shahrani, H., \& Islam, M. (2015). Moringa oleifera as an anti-cancer agent against breast and colorectal cancer cell lines. PLoS One, 10, 1-14.

Alhakmani, F., Kumar, S., \& Khan, S. A. (2013). Estimation of total phenolic content, in-vitro antioxidant and anti-inflammatory activity of flowers of Moringa oleifera. Asian Pacific Journal of Tropical Biomedicine, 3(8), 623-627.

AOAC International (2016). Official Methods of Analysis of AOAC International (20th ed.). AOAC International.

Bancessi, A., Bancessi, Q., Baldé, A., \& Catarino, L. (2020). Present and potential uses of Moringa oleifera as a multipurpose plant in Guinea-Bissau. South African Journal of Botany, 129, 206-208.

Baptista, A. T. A., Silva, M. O., Gomes, R. G., Bergamasco, R., Vieira, M. F., \& Vieira, A. M. S. (2017). Protein fractionation of seeds of Moringa oleifera Lam and its application in superficial water treatment. Separation and Purification Technology, 180, 114-124.

Barros, L., Dueñas, M., Alves, C. T., Silva, S., Henriques, M., Santos-Buelga, C., \& Ferreira, I. C. F. R. (2013). Antifungal activity and detailed chemical characterization of Cistus ladanifer phenolic extracts. Industrial Crops and Products, 41, 41-45.

Bessada, S. M. F., Barreira, J. C. M., Barros, L., Ferreira, I. C. F. R., \& Oliveira, M. B. P. P. (2016). Phenolic profile and antioxidant activity of Coleostephus myconis (L.) Rchb.f.: An underexploited and highly disseminated species. Industrial Crops and Products, 89, 45-51.

Corrêa, R. C. G., de Souza, A. H. P., Calhelha, R. C., Barros, L., Glamoclija, J., Sokovic, M., Peralta, R. M., Bracht, A., \& Ferreira, I. C. F. R. (2015). Bioactive formulations prepared from fruiting bodies and submerged culture mycelia of the Brazilian edible mushroom Pleurotus ostreatoroseus Singer. Food \& Function, 6(7), 2155-2164.

Daba, M. (2016). Miracle Tree: A review on multi-purposes of Moringa oleifera and its implication for climate change mitigation. Journal of Earth Science and Climatic Change, 7, 1-5.

Dhakar, RamChand, Pooniya, BrijendraK, Gupta, M., Maurya, SheoDatta, Bairwa, N., \& Sanwarmal (2011). Moringa : The herbal gold to combat malnutrition. Chron Young Sci, 2(3), 119. https://doi.org/10.4103/2229-5186.90887.

Gopalakrishnan, L., Doriya, K., \& Kumar, D. S. (2016). Moringa oleifera: A review on nutritive importance and its medicinal application. Food Science and Human Wellness, $5(2), 49-56$.

Ilyas, M., Arshad, M. U., Saeed, F., \& Iqbal, M. (2015). Antioxidant potential and nutritional comparison of moringa leaf and seed powders and their tea infusions. Journal of Animal and Plant Sciences, 25, 226-233.

Iyda, J. H., Fernandes, Â., Calhelha, R. C., Alves, M. J., Ferreira, F. D., Barros, L., Amaral, J. S., \& Ferreira, I. C. F. R. (2019). Nutritional composition and bioactivity of Umbilicus rupestris (Salisb.) Dandy: An underexploited edible wild plant. Food Chemistry, 295, 341-349.

Iyda, J. H., Fernandes, Â., Ferreira, F. D., Alves, M. J., Pires, T. C. S. P., Barros, L., Amaral, J. S., \& Ferreira, I. C. F. R. (2019). Chemical composition and bioactive properties of the wild edible plant Raphanus raphanistrum L. Food Research International, 121, 714-722.

Jaja-Chimedza, A., Graf, B. L., Simmler, C., Kim, Y., Kuhn, P., Pauli, G. F., \& Raskin, I. (2017). Biochemical characterization and anti-inflammatory properties of an isothiocyanate-enriched moringa (Moringa oleifera) seed extract. PLoS One, 12, 1-21.

Jung, I. L. (2014). Soluble extract from Moringa oleifera leaves with a new anticancer activity. PLoS One, 9, 1-10.

Kavitha, C., Ramesh, M., Kumaran, S. S., \& Lakshmi, S. A. (2012). Toxicity of Moringa oleifera seed extract on some hematological and biochemical profiles in a freshwater fish, Cyprinus carpio. Experimental and Toxicologic Pathology, 64(7-8), 681-687.

Liang, L., Wang, C., Li, S., Chu, X., \& Sun, K. (2019). Nutritional compositions of Indian Moringa oleifera seed and antioxidant activity of its polypeptides. Food Science and Nutrition, 7, 1754-1760.
Lim, T. K. (2014). Fruits. Edible Medicinal and Non-Medicinal Plants (pp. 453-485). (1st ed.). Dordrecht: Springer.

Lockowandt, L., Pinela, J., Roriz, C. L., Pereira, C., Abreu, R. M. V., Calhelha, R. C., Alves, M. J., Barros, L., Bredol, M., \& Ferreira, I. C. F. R. (2019). Chemical features and bioactivities of cornflower (Centaurea cyanus L.) capitula: The blue flowers and the unexplored non-edible part. Industrial Crops and Products, 128, 496-503.

Luqman, S., Srivastava, S., Kumar, R., Maurya, A. K., \& Chanda, D. (2011). Experimental assessment of Moringa oleifera leaf and fruit for its antistress, antioxidant, and scavenging potential using in vitro and in vivo assays. Evidence-Based Complementary and Alternative Medicine, 2012, 1-12.

Makita, C., Chimuka, L., Steenkamp, P., Cukrowska, E., \& Madala, E. (2016). Comparative analyses of flavonoid content in Moringa oleifera and Moringa ovalifolia with the aid of UHPLC-qTOF-MS fingerprinting. South African Journal of Botany, 105, 116-122.

Medina, S., Collado-González, J., Ferreres, F., Londoño-Londoño, J., Jiménez-Cartagena, C., Guy, A., Durand, T., Galano, J.-M., \& Gil-Izquierdo, A. (2017). Quantification of phytoprostanes - bioactive oxylipins - and phenolic compounds of Passiflora edulis Sims shell using UHPLC-QqQ-MS/MS and LC-IT-DAD-MS/MS. Food Chemistry, $229,1-8$.

Minaiyan, M., Asghari, G., Taheri, D., Saeidi, M., \& Nasr-Esfahani, S. (2014). Anti-inflammatory effect of Moringa oleifera Lam. seeds on acetic acid-induced acute colitis in rats. Avicenna Journal of Phytomedicine, 4, 127-136.

Muyonga, J. H., Nansereko, S., Steenkamp, I., Manley, M., \& Okoth, J. K. (2016). Traditional african foods and their potential to contribute to health and nutrition: Traditional african foods. In H. U. Shekhar, Z. H. Howlader, \& Y. Kabir (Eds.). Exploring the Nutrition and Health Benefits of Functional Foods (pp. 320-346). (2nd ed.). University of Dhaka.

Nouman, W., Anwar, F., Gull, T., Newton, A., Rosa, E., \& Domínguez-Perles, R. (2016). Profiling of polyphenolics, nutrients and antioxidant potential of germplasm's leaves from seven cultivars of Moringa oleifera Lam. Industrial Crops and Products, 83, $166-176$.

Padayachee, B., \& Baijnath, H. (2020). An updated comprehensive review of the medicinal, phytochemical and pharmacological properties of Moringa oleifera. South African Journal of Botany, 129, 304-316.

Pakade, V., Cukrowska, E., \& Chimuka, L. (2013). Comparison of antioxidant activity of Moringa oleifera and selected vegetables in South Africa. South African Journal of Science, 109, 1-5.

Qiao, X., He, W.-n., Xiang, C., Han, J., Wu, L.-J., Guo, D.-a., \& Ye, M. (2011). Qualitative and Quantitative Analyses of Flavonoids in Spirodela polyrrhiza by High-perfor mance Liquid Chromatography Coupled with Mass Spectrometry: Chemical Analysis for Spirodela polyrrhiza by LC/MS. Phytochemical Analysis, 22(6), 475-483.

Ramabulana, T., Mavunda, R. D., Steenkamp, P. A., Piater, L. A., Dubery, I. A., \& Madala, N. E. (2016). Perturbation of pharmacologically relevant polyphenolic compounds in Moringa oleifera against photo-oxidative damages imposed by gamma radiation. Journal of Photochemistry and Photobiology B: Biology, 156, 79-86.

Sánchez-Salcedo, E. M., Tassotti, M., Del Rio, D., Hernández, F., Martínez, J. J., \& Mena P. (2016). (Poly)phenolic fingerprint and chemometric analysis of white (Morus alba L.) and black (Morus nigra L.) mulberry leaves by using a non-targeted UHPLC-MS approach. Food Chemistry, 212, 250-255.

Singh, A. K., Rana, H. K., Tshabalala, T., Kumar, R., Gupta, A., Ndhlala, A. R., \& Pandey, A. K. (2020). Phytochemical, nutraceutical and pharmacological attributes of a functional crop Moringa oleifera Lam: An overview. South African Journal of Botany, 129, 209-220.

Soković, M., Glamočlija, J., Marin, P. D., Brkić, D., \& van Griensven, L. J. L. D. (2010). Antibacterial effects of the essential oils of commonly consumed medicinal herbs using an in vitro model. Molecules, 15, 7532-7546.

Spréa, R. M., Fernandes, Â., Calhelha, R. C., Pereira, C., Pires, T. C. S. P., Alves, M. J., ... Ferreira, I. C. F. R. (2020). Chemical and bioactive characterization of the aromatic plant: Levisticum officinale W.D.J. Koch: A comprehensive study. Food and Function, $11,1292-1303$.

Truchado, P., Vit, P., Ferreres, F., \& Tomas-Barberan, F. (2011). Liquid chromatography-tandem mass spectrometry analysis allows the simultaneous characterization of $\mathrm{C}$-glycosyl and $\mathrm{O}$-glycosyl flavonoids in stingless bee honeys. Journal of Chromatography A, 1218(42), 7601-7607.

Upadhyay, P., Yadav, M. K., Mishra, S., Sharma, P., \& Purohit, S. (2015). Moringa oleifera: A review of the medical evidence for its nutritional and pharmacological properties. International Journal of Research in Pharmacy and Science, 5, 12-16.

Zheng, Y., Wu, J., Peng, X., \& Zhang, Y. (2019). Field-grown Moringa oleifera response to boron fertilization: Yield component, chemical composition of seed-oil and physiology. Industrial Crops and Products, 138, 111449.

Ziani, B. E. C., Rached, W., Bachari, K., Alves, M. J., Calhelha, R. C., Barros, L., \& Ferreira, I. C. F. R. (2019). Detailed chemical composition and functional properties of Ammodaucus leucotrichus Cross. \& Dur. and Moringa oleifera Lamarck. Journal of Functional Foods, 53, 237-247. 